\title{
Consumer Sensory Acceptance of Standard Pre-cooked Hamburger Patties versus Premium Patties
}

\author{
Peter L. Bordi ${ }^{1}$, Hyojin C. Cho ${ }^{1}$, \& Jessica M. MacMartin ${ }^{1}$ \\ ${ }^{1}$ Center for Food Innovation, School of Hospitality Management, The Pennsylvania State University, 124 Mateer \\ Building, University Park, Pennsylvania, 16802 USA \\ Correspondence: Peter L. Bordi, Center for Food Innovation, School of Hospitality Management, The \\ Pennsylvania State University, 124 Mateer Building, University Park, Pennsylvania, 16802, USA. Tel: \\ 814-863-3579. E-mail: plbjr@psu.edu
}

\author{
Received: April 6, $2017 \quad$ Accepted: May 13, $2017 \quad$ Online Published: June 7, 2017 \\ doi:10.5539/jfr.v6n4p40 URL: https://doi.org/10.5539/jfr.v6n4p40
}

\begin{abstract}
Consumers' increasing concerns toward nutrition, health, and sustainable food have influence food industry. Practitioners in the meat product industry and retailers are focusing on premium labeled meat products, such as Certified Angus Beef and grass-fed beef, to meet consumers' demand. Although many consumers assume the premium has better taste and texture, there is little research comparing the sensory attributes of the premium and non-premium burgers. This study compared the sensory attributes of three different hamburger patties: flame broiled pre-cooked beef (non-premium, standard patties), Angus beef, and grass-fed beef patties (premium patties). The results show that participants prefer pre-cooked hamburger patties significantly than Angus and grass-fed patties in initial taste and flavor. Also, this pre-cooked hamburger patties are significantly preferred compared to grass-fed patties in overall quality and overall liking attributes. Other sensory attributes, such as appearance, texture, juiciness, and seasoning, show no significant difference among three different patties. This indicates that the pre-cooked hamburger patties can be preferred than (or compatible to) Angus or grass-fed patties.
\end{abstract}

Keywords: sensory acceptance, hamburger patties, pre-cooked, premium, Angus, grass-fed

\section{Introduction}

Burgers have been and continue to be a staple of the American diet. A foodservice market researchers estimated that more than 9 billion burgers were sold in the United States to consumers at restaurants and other foodservice outlets in 2014 (McLynn, 2015). At casual dining restaurants, consumers choose burgers over higher priced beef entrees (McLynn, 2015). There are numerous choices of burgers given the different combinations of hamburger patties, toppings and sauces. More recently, consumers' increasing concerns over nutrition and health have focused attention on the patties itself: consumers are questioning the breed, origin, and diet and raising of the cattle from which their burgers are made. (Caldwell, 2014).

This relatively recent curiosity has arisen in the wake of larger cultural concerns about the food we eat and how we treat the animals who provide it. The meat industry must be prepared to deal with consumer needs for ethical decision making when it comes to diet. As part of the response toward consumers' concerns about health and sustainability, meat industry principals and their retail customers are focusing on premium labeled meat products (Weber, Heinze, \& DeSoucey, 2008).

One important variety of premium beef is Angus. Angus is a Scottish breed, formerly called Aberdeen Angus. Angus cattle are the one of most common breeds in America because of their high ratio of muscle-to-carcass weight and distinctive marbling (Beam, 2009). The brand "Certified Angus Beef" is not synonymous with Angus beef. Certified Angus beef must meet certain United States Department of Agriculture (USDA) criteria including phenotype or genotype, as well as marbling, rib eye area, hot carcass weight, fat thickness and more (USDA, 2014). Less than $8 \%$ of all beef sold in the United States earns this premium name (Chang, 2009). Retail prices for Certified Angus Beef are approximately 10-15\% higher than non-Angus USDA choice-graded beef. (Chang, 2009).

Grass-fed beef also commands a premium. "Grass-fed" was first used as a technical term to describe meat that 
had not followed standard feeding practice - i.e. fattening cattle with corns or grain. Once considered inferior, because it didn't follow the standard feeding process, grass-fed meat has been perceptually re-positioned so it's now considered to a high-end, premium beef by consumers and retailers with the increase of health and sustainable food consumption. Grass-fed beef is known to have a different nutrient composition than corn- or grain-fed beef, specifically high levels of 18:3 $\alpha$-linoleic acids and n-3 long-chain poly unsaturated fatty acids. This is reflected in the relative price: As of October 2016, the average price for a pound of grass-fed beef patties is $\$ 10.27$ (USDA, 2016a). For corn- or grain-fed beef, approximately $\$ 5.63$ per pound (USDA, 2016b).Some consumers pay a premium for the "grassy" flavor resulting from the difference in feeding practices (Wood, Richardson, Nute, Fisher, Campo, Kasapidou, Sheard, Enser, 2004).

Many fast food chains, family restaurants, and convenience stores continue to use non-premium, pre-cooked, corn-fed hamburger patties. Since the patties are pre-cooked, they are easily and quickly prepared, to further reduce cook time and labor costs, some food services now use rapid-cooking ovens. A rapid-cooking oven uses a combination of convection and microwave technologies to reduce cook time by $30 \%$ or more (Moyer, 2005).

Although the premium hamburger patties (e.g. Angus, grass-fed) have captured consumers' attention, there is little research comparing the sensory attributes of premium and non-premium burgers. The present study investigates if the demand for premium hamburgers and specialty beef is based on improved sensory attributes compared to non-premium hamburger patties. This research aims to discover if Angus beef hamburgers, grass-fed hamburgers and pre-cooked regular hamburgers possess specific desirable sensory attributes, and if significant differences in consumer preference among the three types of patties exists.

\section{Method}

This study compared three different hamburger patties: flame broiled pre-cooked patties, Angus patties and grass-fed patties. We sought to determine whether the flame broiled pre-cooked patties (standard pre-cooked patties) would hold its own against the two premium competitors (Angus and grass-fed patties). This study offered a half portions of all three burgers to each participant. Participants rated each burger on a variety of sensory attributes, as summarized in Table 2 .

\subsection{Equipment}

The pre-cooked patties were prepared using a rapid-cook oven, the TurboChef Tornado (TurboChef, Carrollton, TX, United States). The Tornado is able to reach temperatures of $422^{\circ}$ Celsius ( $792^{\circ}$ Fahrenheit) to cook the patties completely in a short amount of time (Turbochef Tornado, 2013). Suggested cooking times can be found in the TurboChef Tornado manual. Frozen pre-cooked burgers can be prepared in the oven in one minute and 25 seconds for one patty, or one minute and 45 seconds for two patties prepared at the same time. If the pre-cooked burgers are thawed, they can be placed in the TurboChef oven for 40 seconds for one patty, or one minute for two patties.

Raw burgers were cooked on a standard Vulcan char-broiler grill (model number HMCB34-SEFACV, Baltimore, MD, United States). The Angus and the grass-fed patties were placed onto a hot grill and cooked for three minutes on each side. All patties were checked to ensure they reached $74^{\circ} \mathrm{C}\left(165^{\circ} \mathrm{F}\right)$.

\subsection{Materials}

All hamburger patties were originally frozen, then defrosted one night prior to the study. The pre-cooked flame-broiled patties weighed 4 ounces and had the following ingredients: beef, seasoning salt (salt, dextrose, natural flavors, and spice), and natural flavoring. The Angus patties were 1" thick, 12 ounce raw frozen 100\% Certified Angus Beef ground chuck patties. The grass-fed patties were $3 / 4$ " thick, 8 ounce frozen $100 \%$ natural Angus patties. Both the Angus and the grass-fed patties decreased in weight and size when grilled. The reduction of weight in an $80 \%$ lean raw burger when grilled is approximately 31\% (U.S. Department of Agriculture, 2012), resulting in an 8.28 ounce Angus burger and 5.52 ounce grass-fed burger.

\subsection{Participants}

50 untrained panelists were chosen to participate in this research from a listserv at a large university in the northeast. Untrained panelists are ideal for rating preferences amongst hedonic attributes (Lawless \& Heymann, 2010). A majority of the participants were male (60\%) and between the ages of 25-34 (56\%). Age breakdowns are offered in Table 1. 
Table 1. Age groups of participants

\begin{tabular}{lll}
\hline Age Group & Frequency & Percent \\
\hline $18-24$ & 9 & $18.0 \%$ \\
$25-34$ & 28 & $56.0 \%$ \\
$35-45$ & 13 & $26.0 \%$ \\
Total & 50 & $100 \%$ \\
\hline
\end{tabular}

\subsection{Methods}

Hamburgers were prepared as described above, either in a TurboChef oven (pre-cooked burger patties) or on a grill (Angus and grass-fed patties). Researchers prepared the burgers, put them on buns, cut them in half and served them without any condiments or vegetables. Each participant received a tray with one-half of each hamburger and a cup of water to cleanse their palate before starting the test and in between each sample. Ten panelists were able to test at a time in separate booths, answering questions about each individual hamburger on a computer. Participants assessed the following attributes: appearance, initial taste, flavor, texture, juiciness, liking of seasoning, overall quality, and overall liking. Participants were requested to evaluate each hamburger attribute on a 9-point hedonic scale from dislike extremely to like extremely. Participants were also asked to rank the three hamburger types in order from their favorite to least favorite.

\section{Results}

A one-way within subjects analysis of variance (ANOVA) was conducted to verify the difference of sensory attributes three different hamburger patties; pre-cooked, Angus, and grass-fed. Pre-cooked patties are significantly different from Angus and grass-fed patties in initial taste $\left(\mathrm{M}_{\text {pre-cooked }}=6.36, \mathrm{M}_{\text {angus }}=5.48\right.$, $\left.\mathrm{M}_{\text {grass-fed }}=5.42, \mathrm{~F}=5.17, \mathrm{p}<.01\right)$ and in flavor $\left(\mathrm{M}_{\text {pre-cooked }}=6.28, \mathrm{M}_{\text {angus }}=5.36, \mathrm{M}_{\text {grass-fed }}=5.32, \mathrm{~F}=6.53, \mathrm{p}<.01\right)$. Pre-cooked and Angus patties are significantly different from grass-fed patties in overall quality $\left(\mathrm{M}_{\text {pre-cookd }}=6.18\right.$, $\left.\mathrm{M}_{\text {angus }}=5.56, \mathrm{M}_{\text {grass-fed }}=5.32, \mathrm{~F}=3.94, \mathrm{p}<.05\right)$ and overall liking $\left(\mathrm{M}_{\text {Pre-cooked }}=6.28, \mathrm{M}_{\text {angus }}=5.48, \mathrm{M}_{\text {grass-fed }}=5.26\right.$, $\mathrm{F}=5.26, \mathrm{p}<.01)$. However, there is no significant differences in three patties in liking of appearance $\left(\mathrm{M}_{\text {pre-cooked }}=5.62, \mathrm{M}_{\text {angus }}=5.66, \mathrm{M}_{\text {grass-fed }}=5.38, \mathrm{~F}=.57, \mathrm{p}=.57\right)$, texture $\left(\mathrm{M}_{\text {Pre-cooked }}=5.84, \mathrm{M}_{\text {angus }}=5.38, \mathrm{M}_{\text {grass-fed }}=5.20\right.$, $\mathrm{F}=1.86, \mathrm{p}=.17)$, juiciness $\left(\mathrm{M}_{\text {Pre-cooked }}=6.16, \mathrm{M}_{\text {angus }}=5.78, \quad \mathrm{M}_{\text {grass-fed }}=5.88, \mathrm{~F}=.97, \mathrm{p}=.38\right)$, and seasoning $\left(\mathrm{M}_{\text {pre-cooked }}=5.94, \mathrm{M}_{\text {angus }}=5.38, \mathrm{M}_{\text {grass-fed }}=5.22, \mathrm{~F}=2.89, \mathrm{p}=.064\right)$. The summary of sensory attribute data can be found in Table 2.

Table 2. Attribute $\dagger$ Mean Comparison among Pre-cooked, Angus, and grass-fed Hamburger Patties

\begin{tabular}{cccccc}
\hline & pre-cooked $M(S D)$ & Angus $M(S D)$ & grass-fed $M(S D)$ & $\mathrm{F}$ & p-value \\
\hline Appearance & $5.62^{\mathrm{a}}(1.63)$ & $5.66^{\mathrm{a}}(1.59)$ & $5.38^{\mathrm{a}}(1.60)$ & .568 & .567 \\
Initial Taste & $6.36^{\mathrm{a}}(1.52)$ & $5.48^{\mathrm{b}}(1.54)$ & $5.42^{\mathrm{b}}(1.81)$ & 5.173 & $.009^{*}$ \\
Flavor & $6.28^{\mathrm{a}}(1.36)$ & $5.36^{\mathrm{b}}(1.40)$ & $5.32^{\mathrm{b}}(1.87)$ & 6.534 & $.002^{*}$ \\
Texture & $5.84^{\mathrm{a}}(1.72)$ & $5.38^{\mathrm{a}}(1.68)$ & $5.20^{\mathrm{a}}(1.88)$ & 1.855 & .167 \\
Juiciness & $6.16^{\mathrm{a}}(1.57)$ & $5.78^{\mathrm{a}}(1.53)$ & $5.88^{\mathrm{a}}(1.71)$ & .969 & .381 \\
Seasoning & $5.94^{\mathrm{a}}(1.66)$ & $5.38^{\mathrm{a}}(1.48)$ & $5.22^{\mathrm{a}}(1.79)$ & 2.89 & .064 \\
Overall Quality & $6.18^{\mathrm{a}}(1.49)$ & $5.56^{\mathrm{a}}(1.64)$ & $5.32^{\mathrm{b}}(1.93)$ & 3.939 & $.026^{*}$ \\
Overall Liking & $6.28^{\mathrm{a}}(1.46)$ & $5.48^{\mathrm{a}}(1.68)$ & $5.26^{\mathrm{b}}(1.94)$ & 5.258 & $.009^{*}$ \\
\hline
\end{tabular}

$\dagger$ Nine-point hedonic scale: $1=$ dislike extremely, $2=$ dislike very much, $3=$ dislike moderately, 4=dislike slightly, $5=$ neither like nor dislike, $6=$ like slightly, $7=$ like moderately, $8=$ like very much, $9=$ like extremely

$* \mathrm{p}<0.05$

${ }^{\mathrm{ab}}$ Means within a row with different superscripts are significantly different $(\mathrm{p}<0.05)$

\section{Discussion/Conclusion}

This study investigated the differences in sensory acceptance among three different hamburger patties; pre-cooked, Angus, and grass-fed. The results show that participants preferred pre-cooked hamburger patties to Angus and grass-fed patties in: initial taste, flavor, overall quality and overall liking. Other sensory attributes, such as appearance, texture, juiciness, and seasoning, show no significant difference among the three types of patties. This indicates that the pre-cooked hamburger patties cooked in a rapid-cook oven are preferred more than or equally to Angus or grass-fed patties cooked on a conventional grill. These results show that consumers may not recognize (or care about) the superior sensory attributes of the premium burger patties. 


\section{Limitation/Future Studies}

Since this study focuses on three different hamburger patties used in restaurants, the preparation and cooking conditions were designed to resemble the industry's general practice. The pre-cooked patties currently used in food industry are mostly seasoned while premium raw burger patties are not seasoned. Thus this study used seasoned pre-cooked patties and unseasoned premium burger patties. Also, a rapid-cook oven was used for cooking the pre-cooked patties, while a conventional grill was used for cooking the raw premium patties. Since the cooking mirrored industry practice, this study result would be helpful for practitioners. However, for more accurate comparisons, future researchers should control the material and cooking procedure differences.

\section{Funding Sources/Conflict of Interest}

This research did not receive any specific grant from funding agencies in the public, commercial or not-for-profit sectors.

\section{References}

Beam, C. (2009, October 7). Holy Cow: What's So Good About Angus Beef? Slate, Retrieved from http://www.slate.com/articles/news_and_politics/explainer/2009/10/holy_cow.html

Caldwell, M. (2014). The rise of the gourmet hamburger. Contexts, 13, 72-74. https://doi.org/10.1177/1536504214545765

Chang, A. (2009). Angus beef can be found in your local grocery store and many fast food chains, but is it worth the higher cost? The Street. Retrieved from https://www.thestreet.com/story/12803768/1/should-you-pay-extra-angus-beef.html

Lawless, H. T., \& Heymann, H. (2010). Sensory evaluation of food: Principles and practices ( $2^{\text {nd }}$ ed.). New York: Springer. https://doi.org/10.1007/978-1-4419-6488-5

McLynn, K. (2015, January 27). Restaurant Burgers Had A Banner Year in 2014, Reports NPD. Retrieved from https://www.npd.com/wps/portal/npd/us/news/press-releases/2015/restaurant-burgers-had-a-banner-year-in2014

Moyer, L. (2005). Fast-cook ovens cook food in minutes. Retrieved from http://www.nbcnews.com/id/9839623/ns/technology_and_science-tech_and_gadgets/t/fast-cook-ovens-cook -ovens-cook-food-minutes

TurboChef. (2013). Tornado: Tornado and Tornado 2 (NGC) Ventless Submittal Information. Retrieved from http://www.turbochef.com/filemanager/36/NGC_Ventless_Submittal_Package.pdf

United States Department of Agriculture (2016a). National Monthly Grass Fed Beef Report. Retrieved from https://www.ams.usda.gov/mnreports/lsmngfbeef.pdf

United States Department of Agriculture (2016b). Meat Price Spreads. Retrieved from https://www.ers.usda.gov/data-products/meat-price-spreads.aspx

United States Department of Agriculture, Agricultural Research Service. (2012). USDA Table of Cooking Yields for Meat and Poultry. Nutrient Data Laboratory Home Page. Retrieved from https://www.ars.usda.gov/ARSUserFiles/80400525/Data/retn/USDA_CookingYields_MeatPoultry.pdf

United States Department of Agriculture. (2014). USDA Specification for Certification of Beef Carcass Quality and Yield Characteristics of Officially Graded Beef. Retrieved from https://www.ams.usda.gov/sites/default/files/media/G-133\%20--WR\%20Reserve\%20Premium\%20Black\% 20Angus\%20Natural\%20Beef.pdf

Weber, K., Heinze, K. L., \& DeSoucey, M. (2008). Forage for thought: Mobilizing codes in the movement for grass-fed meat and dairy Products. Administrative Science Quarterly, 53(3), 529-567. https://doi.org/10.2189/asqu.53.3.529

Wood, J. D., Richardson, R. I., Nute, G. R., Fisher, A. V., Campo, M. M., Kasapidou, E., ... \& Enser, M. (2004). Effects of fatty acids on meat quality: a review. Meat science, 66(1), 21-32. https://doi.org/10.1016/S0309-1740(03)00022-6

\section{Copyrights}

Copyright for this article is retained by the author(s), with first publication rights granted to the journal.

This is an open-access article distributed under the terms and conditions of the Creative Commons Attribution license (http://creativecommons.org/licenses/by/3.0/). 